\title{
Effect of Particulate Matter 2.5 on Airway Inflammation and Mucus Hyper secretion of Chronic Obstructive Pulmonary Disease
}

\author{
YIFAN DAI, ZHAOYANG RUAN, JIANJUN WANG, ZHANGDAN HUANG, ZEHAI XIA, QINXIA ZHANG AND QUN LV* \\ Department of Respiratory Medicine, The Affiliated Hospital of Hangzhou Normal University, No. 126 Wenzhou Road, \\ Hangzhou, Zhejiang 310000, China
}

Dai et al.: Effect of PM2.5 on airway inflammation and mucus hyper secretion of COPD

\begin{abstract}
To study the effect of Particulate Matter 2.5 on airway inflammation and mucus hyper secretion in Chronic obstructive pulmonary disease patients. Particulate Matter 2.5 was collected by particulate samplers and prepared into 30, 300, $3000 \mu \mathrm{g} / \mathrm{ml}$ Particulate Matter 2.5 solution. Normal human lung epithelial cells were treated with Phosphate-buffered saline solution for $12 \mathrm{~h}, 48 \mathrm{~h}$ and $96 \mathrm{~h}$. The cells viability was measured by Cell Counting Kit-8. Quantitative Polymerase Chain Reaction was used to measure the Micro Ribonucleic acid contents of Interleukin 1 beta, Interleukin 8, tumor necrosis factor-beta in BEAS2B cells after Particulate Matter 2.5 treatment. Chronic Obstructive Pulmonary Disease patients $(\mathrm{N}=200)$ from the Affiliated Hospital of Hangzhou Normal University from January 2019 to December 2019 were enrolled and randomly grouped into low exposure group and high exposure group. Before treatment and 6 mo after treatment, forced expiratory volume at $1 \mathrm{~s} /$ forced vital capacity and forced expiratory volume $1 \%$ prediction were detected. Cough and Sputum Assessment Questionnaire scale was conduct to assess the mucus hyper secretion of patients. Particulate Matter 2.5 could significantly inhibit the activity of bronchial epithelial cells Normal human lung epithelial cells cells in a time-dependent and concentrationdependent manner $(\mathbf{p}<\mathbf{0 . 0 5})$. Moreover, Particulate Matter 2.5 could significantly increase the expression of Interleukin 1 beta, Interleukin 8 and tumor necrosis factor-beta in bronchial epithelial cells Normal human lung epithelial cells cells $(\mathbf{p}<\mathbf{0 . 0 5})$, and the higher the concentration of Particulate Matter 2.5 and the longer the action time, the more significant the proinflammatory effect was. The forced expiratory volume 1/forced vital capacity and forced expiratory volume $1 \%$ prediction of Chronic Obstructive Pulmonary Disease patients with high Particulate Matter 2.5 exposure were significantly lower than that of patients with low Particulate Matter 2.5 exposure $(p<0.05)$, and the Cough and Sputum Assessment Questionnaire scores were significantly increased $(p<0.05)$. High and long-term exposure to Particulate Matter 2.5 can reduce the activity of pulmonary epithelial cells in a time and concentration dependent manner, and significantly increase the expression levels of inflammatory factors such as Interleukin 1 beta, Interleukin 8, tumor necrosis factor-beta. The proinflammatory effects showed a time-dependent and concentration-dependent manner. High exposure to Particulate Matter 2.5 can damage the lung function of Chronic Obstructive Pulmonary Disease patients and increase the secretion of airway mucus.
\end{abstract}

Key words: PM2.5, Chronic obstructive pulmonary disease, inflammation, lung function, mucus hyper secretion

Chronic obstructive pulmonary disease (COPD) is a progressive condition characterized by incomplete reversible airflow limitation with an enhanced chronic inflammatory response ${ }^{[1]}$. The incidence, mortality and disability rate of COPD ranked high among all diseases, COPD is associated with complication that induce further negative effect on quality of life and prognosis $^{[2]}$, deteriorating patients' living quality and society's stable seriously. COPD has many risk factors including tobacco smoke, chemicals, occupational dusts, biomass fuel and air pollution ${ }^{[3]}$. Fine particulate matter (PM2.5) is associated to some risk factors as air pollution and occupational dusts. PM2.5 refers to the aerodynamic equivalent diameter less than or equal to $2.5 \mu \mathrm{m}$ in the atmosphere, also known as pulmonary particulate matter. Compared with other

*Address for correspondence

E-mail: wenlin264161@163.com 
air pollutants, PM2.5 has small particle size, large surface area, toxic and harmful substances, and can directly enter alveoli and blood ${ }^{[4]}$. There are a few studies on the effect of PM2.5 on respiratory diseases in China, but there are few relevant researches on the effect of PM2.5 on airway mucus hyper secretion and pulmonary function in patients with COPD. The death risk of COPD caused by airway mucus hyper secretion is 3.5 times of non-airway mucus hyper secretion ${ }^{[5]}$. In this article, we studied the effects of PM2.5 on cells viability and secretion of inflammatory factor of human lung epithelial cells under diverse exposure time and concentration .Moreover, the effect of PM2.5 on airway mucus hyper secretion and pulmonary function in patients with COPD were studied, aiming to provide evidence and reference for the prevention and treatment of COPD .

\section{MATERIALS AND METHODS}

\section{Materials:}

Normal human lung epithelial cells: (BEAS-2B cells) (ATCC, Cat. \#. YB-ATCC-9348), LHC-9 Medium (Gibco, Cat. \#.12680-013), Human Interleukin-1 (IL-1) PCR Kit (Shanghai Yaji Biotechnology Co., Ltd, Cat.\#. YS01052P), Human Interleukin-8 (IL-8) PCR Kit (Shanghai Yaji Biotechnology Co., Ltd., Cat.\#.YS01100P), Cell Counting Kit8 (Medchemexpress, Cat. \#. HY-K0301), Total ribonucleic acid (RNA) Extraction Kit (Solarbio, Cat.\#. R1200), Quantitect Reverse Transcription Kit (Qiagen, Cat.\# 205311), Fetal Bovine Serum (FBS) (GIBCO, Cat.\#. 10099-141), glass fiber filters (watman, UK), Particulate Samplers (Airborne, USA), Nanodrop 1000 spectroscopy (Thermo Fisher,USA), $\mathrm{CO}_{2}$ cell incubator (Thermo, USA), Microplate Reader (Thermo, USA) and MSA99 lung function analyzer (Beijing B \& M, China).

\section{Collection of PM2.5:}

PM2.5 was continuously collected by particulate samplers on glass fiber filters at the top of our hospital.
After collecting, the filters were cut into $1 \mathrm{~cm} \times 1 \mathrm{~cm}$ square and put into sterile water. The filters were done ultrasonic extraction for 3 times, 10 min each time, the suspension containing air particles was lyophilized and weighed and stored at $-20 \pi$.

\section{Cell cultures and treatment:}

BEAS-2B cells were resuscitated and cultured in LHC9 medium containing $10 \%$ fetal bovine serum at $37 \pi$ and $5 \% \mathrm{CO}_{2}$. When BEAS-2B cells overspread more than $80 \%$ of the culture dish, trypsin was added for digestion and cell suspension was washed by Phosphatebuffered saline solution and collected by centrifugation. BEAS-2B cells were transferred into 6 -well plates at a density of $1.5 \times 10^{5}$ cells $/ \mathrm{ml}$ and cultured overnight in serum-free LHC-9 medium. The PM2.5 sample was weighed and diluted with PBS into $(0,30,300$, $3000 \mu \mathrm{g} / \mathrm{ml}$ ) PM2.5 solution. PM2.5 solution with different concentration was added to cells, and 6 multiple pores were set for each concentration. After $48 \mathrm{~h}$ treatment, BEAS-2B cells were washed twice with PBS solution and harvested by centrifugation. For the $300 \mu \mathrm{g} / \mathrm{ml}$ PM2.5 group, BEAS-2B cells were harvested at $12 \mathrm{~h}$ or $96 \mathrm{~h}$ additionally.

\section{Measurement the cells viability by CCK-8:}

The harvested cells in each group were added with $10 \mu 1$ CCK- 8 solution and incubated at $5 \% \mathrm{CO}_{2}$ and $37 \pi$ for $3 \mathrm{~h}$. The optical density (OD) values of each well were detected by Micro plate Reader at $450 \mathrm{~nm}$.

\section{Measurement the messenger ribonucleic acid (mRNA) content of IL-1 $\beta$, IL-8, TNF- $\beta$ by qPCR:}

Total RNAs in diverse PM2.5 treated BEAS-2B cells were extracted by kit according to the manufacturer's recommendations and analyzed the quantity and purity by spectrophotometry. The RNAs were reverse transcript into Complementary DNA using the Reverse Transcription kit. All cDNAs were analyzed the expression level of IL-1 $\beta$, IL- 8 , TNF- $\beta$ by qPCR. $\beta$-actin was tested as control. The prime sequences were attached in (Table 1).

\section{TABLE 1: THE PRIME SEQUENCES FOR QPCR}

\begin{tabular}{|c|c|c|}
\hline Items & Forward prime & Reverse prime \\
\hline IL-1B & $\begin{array}{c}\text { 5'-TGGCCTGCACAGTGAAGTGC } \\
\text { TG-3' }\end{array}$ & $\begin{array}{c}5^{\prime} \text {-TGGCCAGCTCCGGGACTCA } \\
\text { CA-3' }\end{array}$ \\
\hline IL-8 & $\begin{array}{c}\text { 5'-TAGGCACTCCGGGACGACGC } \\
\text { ACA-3' }\end{array}$ & $\begin{array}{c}\text { 5'-TAGAAATTGCCAATCCTTTC } \\
\text { CACC-3' }\end{array}$ \\
\hline TNF-B & 5'-CGAGTGACAAGCCTGTAGC-3' & $\begin{array}{c}\text { 5'-GGTGTGGGTGAGGAGCACA } \\
\text { T-3' }\end{array}$ \\
\hline B-actin & $\begin{array}{c}\text { 5'-GTAGTTTCGTGGATGCCACA } \\
\text { G-3' }\end{array}$ & $\begin{array}{c}\text { 5'-GAGCTACGAGCTGCCTGAC } \\
\text { G-3' }\end{array}$ \\
\hline
\end{tabular}




\section{Recruition and grouping of COPD patients:}

This investigation enrolled COPD patients from the Affiliated Hospital of Hangzhou Normal University from January 2019 to December 2019.

Inclusion criteria are listed as below: the age of patients was $\geq 18$ y old; $<80 \mathrm{y}$ old; the diagnosis of COPD was confirmed according to the Global Initiative for Chronic Obstructive Lung Disease ${ }^{[6]}$; Grading Obstructive Lung Disease 1 grade; signed informed consent.

Exclusion criteria are listed as below: Patients have no settled abode; smoking or frequently exposure to smoking; Complication with other severe disease; Patients with cognitive difficult, mental illness or other condition that can't obey treatment and follow-up.

According to PM2.5 data (http://www.pm25china.net/) of Hangzhou City from June 2018 to March 2019, the average PM2.5 in Gongshu District was significantly higher than Qiandaohu District (64 vs 13, p<0.05). Patients $(\mathrm{N}=100)$ lived in Xiaoshan District were distributed to high exposure group, while patients $(\mathrm{N}=100)$ lived in Qiandaohu District were distributed to low exposure group.

They were randomly divided into low exposure group $(\mathrm{N}=100)$ and high exposure group $(\mathrm{N}=100)$. Both groups received regular treatment. In the low exposure group, there were 67 males and 33 females, the age ranged from 55 to $79 \mathrm{y}$ with an average age of $(67.3 \pm 7.2) \mathrm{y}$. The course of COPD ranged from 2 to $18 \mathrm{y}$ with an average course of $(6.4 \pm 2.1) \mathrm{y}$. In the high exposure group, there were 65 males and 35 females, the age ranged from 52 to $78 \mathrm{y}$ with an average age of $(68.2 \pm 6.9)$ y. The course of COPD ranged from 1 to $19 \mathrm{y}$ with an average course of $(6.3 \pm 1.8) \mathrm{y}$. There was no significant difference in gender, age and course of COPD between the two groups ( $p>0.05$ ). This study has been approved by the Ethics Committee of the Affiliated Hospital of Hangzhou Normal University.

\section{Analysis of Lung function and mucus hyper secretion:}

Before treatment and 6 mo after treatment, MSA99 Lung Function Tester was used to detect forced expiratory volume at 1s (FEV1)/forced vital capacity (FVC) and FEV1 \% prediction.

Mucus hyper secretion were assessed by cough and sputum assessment questionnaire (CASA-Q) $)^{[7]}$. The CASA-Q scale has four items including cough symptoms, cough effects, expectoration symptoms, and expectoration effects. Each item is answered on a scale from 'never' to 'always' (for frequency) or from 'not at all' to 'a lot/extremely' (for intensity). All items are rescored from 1-5 to 0-4. Scores were summed and rescaled using the following algorithm: (sum rescored items)/(range of rescored item sum $) \times 100$. Higher scores associated with lower mucus hyper secretion.

\section{Statistical analysis:}

SPSS 22.0 software was used for statistical analysis. Data were present as $(\mathrm{x} \pm \mathrm{s})$. Student's T-test was used for comparison between two groups, $\mathrm{p}<0.05$ means there was statistical significance between different groups.

\section{RESULTS AND DISCUSSION}

BEAS-2B cells were incubated with different concentrations of PM2.5 $(0,30,300,3000 \mu \mathrm{g} / \mathrm{ml})$ respectively. The results of CCK- 8 showed that PM2.5 could significantly inhibit BEAS-2B cells viability $(p<0.05)$, and the inhibitory effect was concentrationdependent, as shown in (fig. 1A).

BEAS-2B cells were treated with $300 \mu \mathrm{g} / \mathrm{ml}$ PM2.5 for $0,12,48$ and $96 \mathrm{~h}$. The results showed that PM2.5 could significantly inhibit BEAS-2B cell activity $(\mathrm{p}<0.05)$, and the inhibitory effect was time-dependent, as shown in (fig. 1B).

qPCR was used to analyze the mRNA content of IL- $1 \beta$, IL- 8 and TNF- $\beta$ in BEAS- $2 B$ cells after exposure to differnent concentrations of PM2.5. As shown in (fig. 2), the mRNA content of IL-1 $\beta$, IL-8 and TNF- $\beta$ were all increased by PM 2.5 concentration-dependent manner $(\mathrm{p}<0.05)$.

Moreover, the mRNA content of IL- $1 \beta$, IL- 8 and TNF- $\beta$ in BEAS-2B cells treated with $300 \mu \mathrm{g} / \mathrm{ml} \mathrm{PM} 2.5$ for $0,12,48$ and $96 \mathrm{~h}$ were analyzed using quantitative Polymerase Chain Reaction (qPCR). The results showed that PM2.5 could significantly increase the expression of IL- $1 \beta$, IL- 8 and TNF- $\beta$ in BEAS- $2 B$ cells $(p<0.05)$, and the increase effect was time-dependent, as shown in (fig. 3).

FEV1/FVC and FEV1\% prediction of COPD patients under different PM2.5 exposure were detected by MSA99 lung function analyzer. As shown in (Table 2), The FEV1/FVC (\%) and FEV1\% prediction had no significant difference between low exposure group and high exposure group before treatment $(p>0.05)$, indicating that the two groups were comparable for lung function. After 6 mo exposure to 
$\mathbf{A}$

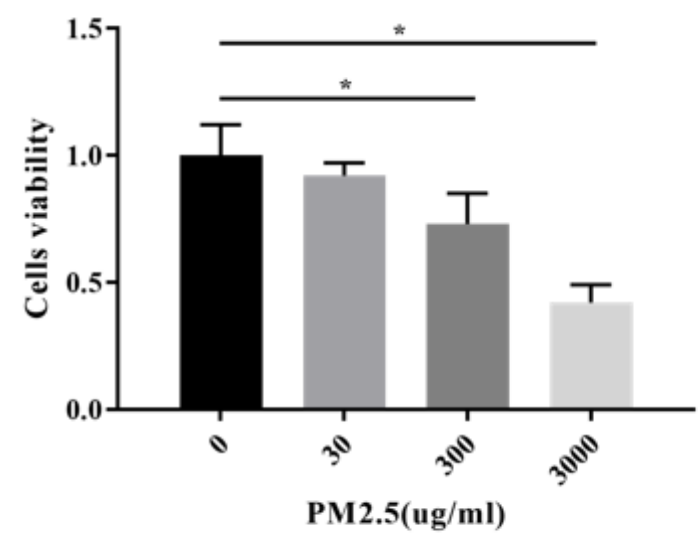

B

CCK-8

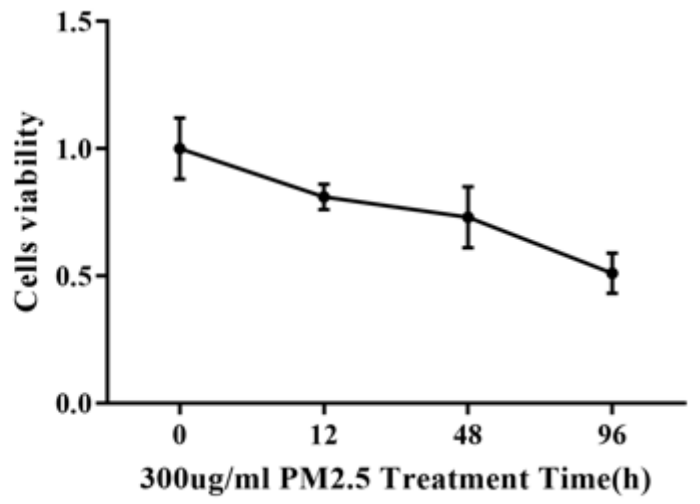

Fig. 1: The effect of PM2.5 on the viability of BEAS-2B cells $\left(\mathrm{n}=6^{*}: \mathrm{p}<0.05\right.$ vs $0 \mu \mathrm{g} / \mathrm{ml}$ PM 2.5)

$\mathbf{A}$

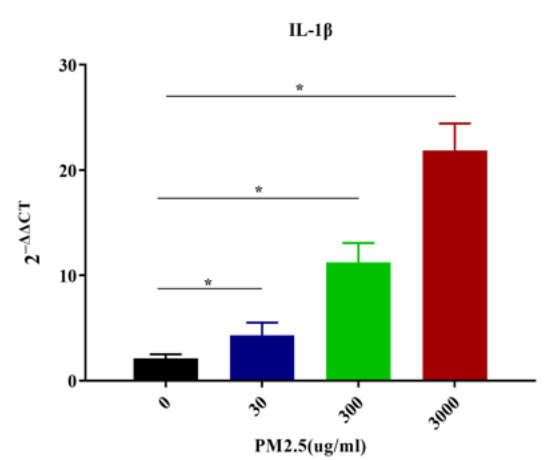

B

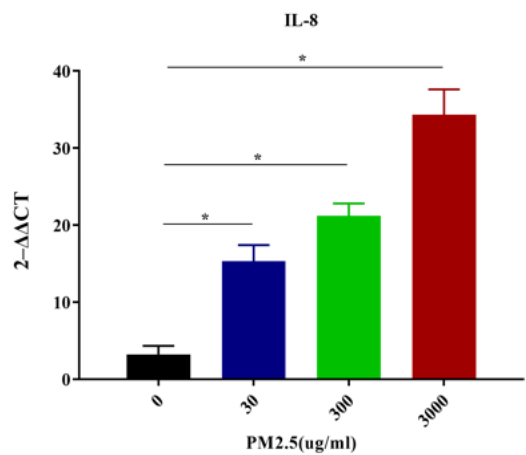

C

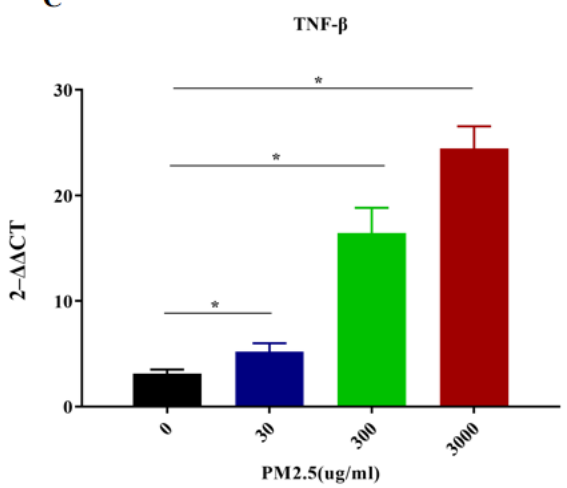

Fig. 2: The effect of PM2.5 on mRNA of IL-1 $\beta$, IL-8 and TNF- $\beta$ in BEAS-2B cells $(n=6 *:$ p $<0.05$ vs $0 \mu \mathrm{g} / \mathrm{ml}$ PM 2.5)

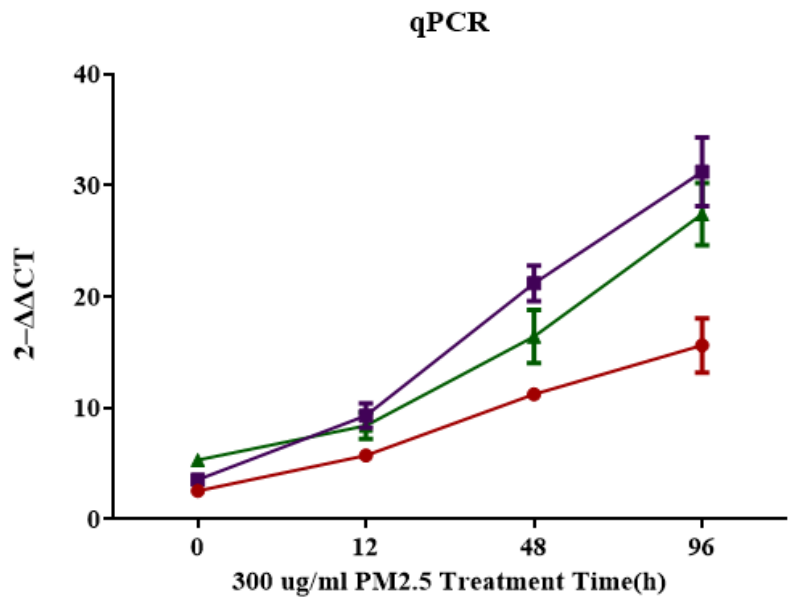

Fig. 3: The effect of PM2.5 on expression of IL-1ß, IL-8 and TNF- $\beta$ in BEAS-2B cells $(n=6 *: p<0.05$ vs $0 h)$

PM2.5 environment, the FEV1/FVC (\%) and FEV1\% prediction of low exposure group were both higher than that of the high exposure group $(\mathrm{p}<0.05)$, suggesting that high PM2.5 could decline the lung function of COPD patients and reduce treatment efficacy.

Mucus hyper secretion of patients under different PM2.5 exposure was assessed by CASA-Q Scale. As shown in (Table 3), The CASA-Q scores had no significant difference between low exposure group and high exposure group before treatment $(\mathrm{p}>0.05)$, indicating that the two groups were comparable to assess mucus hyper secretion. After 6 mo exposure to low or high PM2.5 environment, the CASA-Q scores of low exposure group were both higher than that of the high exposure group $(\mathrm{p}<0.05)$.

COPD, a high morbidity and fatality rate disease characterized by progressive and irreversible airflow limitation. The global morbidity rate of COPD was $11.70 \%$ in 2015 , and the mortality rate ranked number four in all diseases, higher than that of lung cancer ${ }^{[8]}$. According to "Global Burden of Disease Study" by WHO, COPD will become the third cause of death by 
TABLE 2: LUNG FUNCTION BETWEEN TWO GROUPS ( $x \pm s)$

\begin{tabular}{|c|c|c|c|c|c|}
\hline \multirow{2}{*}{ Group } & \multirow{2}{*}{$\mathbf{N}$} & \multicolumn{2}{|c|}{ FEV1/FVC (\%) } & \multicolumn{2}{|c|}{ FEV1 \% prediction } \\
\hline & & 0 month & 6 month & 0 month & 6 month \\
\hline Low exposure group & 100 & $52.60 \pm 11.03$ & $58.42 \pm 10.55$ & $55.04 \pm 12.76$ & $61.92 \pm 12.10$ \\
\hline High exposure group & 100 & $52.14 \pm 11.36$ & $55.32 \pm 10.30$ & $55.56 \pm 11.63$ & $57.62 \pm 11.53$ \\
\hline $\mathrm{t}$ & & 0.291 & 2.103 & 0.301 & 2.573 \\
\hline $\mathrm{p}$ & & 0.772 & 0.037 & 0.764 & 0.011 \\
\hline
\end{tabular}

TABLE 3: CASA-Q SCORES BETWEEN TWO GROUPS ( $x \pm s)$

\begin{tabular}{lccc}
\hline \multirow{2}{*}{ roup } & $\mathrm{N}$ & $\mathbf{0}$ & $\mathrm{C}$ month \\
\cline { 3 - 4 } Low exposure group & 100 & $24.37 \pm 3.52$ & $56.43 \pm 4.77$ \\
High exposure group & 100 & $25.31 \pm 4.31$ & $47.52 \pm 3.64$ \\
$T$ & & 1.689 & 14.847 \\
$\mathrm{P}$ & & 0.093 & 0.000 \\
\hline
\end{tabular}

$2020^{[9]}$. COPD is associated with enhanced chronic inflammatory response of airway and lung to toxic particles as PM 2.5. Li MH et al. ${ }^{[10]}$ found that short-term exposure to PM2.5 increased the hospitalization and mortality rate of COPD patients. PM2.5 can stimulate the secretion of Mucin 5AC (MUC5AC) in bronchial and alveolar epithelial cells, resulting in airway mucus hyper secretion and chronic airway inflammatory diseases ${ }^{[11]}$. Roy A et al. ${ }^{[12]}$ found that exposure to PM2.5 was harmful to the recovery of lung function in COPD patients, and the increase of PM2.5 concentration was significantly related to the number of emergency and outpatient patients. More importantly, PM2.5 is related to the hospitalization rate and mortality of patients with COPD. The peak expiratory flow of COPD patients exposed to PM2.5 environment decreased significantly, and the respiratory symptoms increased heavily ${ }^{[13]}$.

Our study aimed to study the relationship and mechanism of PM2.5 on COPD. BEAS-2B cells, one kind of human normal lung epithelial cells, were co-incubated with diverse concentrations of PM2.5 for different periods, then cellular activity and inflammatory factors were measured using CCK-8 and qPCR methods. The results showed that $\mathrm{PM} 2.5$ could significantly inhibit the activity of BEAS-2B cells in time-dependent and concentration-dependent manner. Moreover, PM2.5 could significantly increase the expression of IL- $1 \beta$, IL- 8 and TNF- $\beta$ in BEAS-2B cells, and the higher the concentration of PM2.5 and the longer the action time, causing the more significant the pro-inflammatory effect. Our in vitro results were consistent with other articles, such as Oh et al. ${ }^{[14]}$ and Fuentes Mattei et al. ${ }^{[15]}$. Oh Found that PM2.5 has toxic effects on BEAS-2B cells in vitro. Reactive oxygen species may play an important role in the toxic effects. Aliphatic/chlorinated hydrocarbons, polycyclic aromatic hydrocarbons, nitro polycyclic aromatic hydrocarbons/ketone/quinones in PM2.5 may associate with the toxic effects. Fuentes Mattei proved that the organic components and bioactive components of PM2.5 could regulate the secretion of cytokines in BEAS-2B cells, thus regulating the inflammatory response of the lung and participating in the development of respiratory inflammatory diseases. In addition, Gualtieri et al. ${ }^{[16]}$ also used BEAS-2B cells to study the difference of cytotoxicity and proinflammatory effect of different components in PM2.5, and concluded that different components of PM2.5 may lead to different toxic effects, such as inflammatory reaction, and even cell death.

In addition, this study compared the effects between different PM2.5 exposure on lung function and mucus hyper secretion in COPD patients $(\mathrm{N}=200)$ through prospective study. The results showed that the lung function of COPD patients with high exposure to PM2.5 was significantly lower than that of patients with low exposure to PM2.5, and the mucus secretion was significantly increased when patients under high PM2.5. The mucus clearance function of COPD patients usually decline, making a large amount of mucus accumulation in the lung to induce continuous airflow restriction, repeated airway infection, which seriously affect the quality of life of patients. Airway mucus hyper secretion is a high risk factor of COPD, an important component of accelerating disease progression and a limiting factor affecting the prognosis of patients.

In conclusion, high and long-term exposure to PM2.5 can reduce the activity of pulmonary epithelial cells in a time and concentration dependent manner, and significantly increase the expression levels of inflammatory factors such as IL- $1 \beta$, IL- 8 , TNF- $\beta$. The proinflammatory effects showed a time-dependent and 
concentration-dependent manner. High exposure to PM2.5 can damage the lung function of COPD patients and increase the secretion of airway mucus.

\section{Authors' contributions:}

QUN LV conceived and designed the experiments; Z. RUAN, J. WANG, ZHANGDAN HUANG, ZEHAI XIA and QINXIA ZHANG performed the experiments; Y. DAI analyzed the data and wrote the paper.

\section{Acknowledgement}

This work was supported by the Affiliated Hospital of Hangzhou Normal University.

\section{Conflicts of interest}

The authors report no conflicts of interest..

\section{REFERENCES}

1. Plishka CT, Rotter T, Penz ED, Hansia MR, Fraser SK, Marciniuk DD, et al. Effects of Clinical Pathways for COPD on Patient, Professional, and Systems Outcomes: A Systematic Review. Chest 2019;156:864-77.

2. Tiew PY, San Ko FW, Narayana JK, Poh ME, Xu H, Neo HY, et al. 'High risk' clinical and inflammatory clusters in COPD of Chinese descent. Chest. 2020;158:145-156.

3. Njoku CM, Alqahtani JS, Wimmer BC, Peterson GM, Kinsman $\mathrm{L}$, Hurst JR, et al. Risk factors and associated outcomes of hospital readmission in COPD: A systematic review. Respir Med 2020:105988.

4. Li Y, Zhou J, Rui X, Zhou L, Mo X. PM2. 5 exposure exacerbates allergic rhinitis in mice by increasing DNA methylation in the IFN- $\gamma$ gene promoter in CD4+ T cells via the ERK-DNMT pathway. Toxicol Lett 2019;301:98-107.

5. Hogg JC, Chu FS, Tan WC, Sin DD, Patel SA, Pare PD, et al. Survival after lung volume reduction in chronic obstructive pulmonary disease: insights from small airway pathology. Am J Respir Crit Care Med 2007;176:454-9.

6. Vogelmeier CF, Criner GJ, Martinez FJ, Anzueto A, Barnes $\mathrm{PJ}$, Bourbeau J, et al. Global strategy for the diagnosis, management, and prevention of chronic obstructive lung disease 2017 report. GOLD executive summary. Am J Respir Crit Care Med 2017;195:557-82.

7. Crawford B, Monz B, Hohlfeld J, Roche N, Rubin B, Magnussen $\mathrm{H}$, et al. Development and validation of a cough and sputum assessment questionnaire. Respiratory medicine 2008;102:1545-55.

8. Adeloye D, Chua S, Lee C, Basquill C, Papana A, Theodoratou $\mathrm{E}$, et al. Global and regional estimates of COPD prevalence: Systematic review and meta-analysis. J Glob Health 2015;5:020415.

9. Nielsen LO, Olsen S, Jarbøl DE, Pedersen ML. Spirometry in Greenland: a cross-sectional study on patients treated with medication targeting obstructive pulmonary disease. Int J Circumpolar Health $2016 ; 75: 33258$.

10. Liu MH, Chan MJ, Hsu CW, Weng CH, Yen TH, Huang WH. Association of uremic pruritus in hemodialysis patients with the number of days of high mean 24-hour particulate matter with a diameter of $<2.5 \mu \mathrm{m}$. Ther Clin Risk Manag 2017;13:255-62.

11. Feng S, Duan E, Shi X, Zhang H, Li H, Zhao Y, et al. Hydrogen ameliorates lung injury in a rat model of subacute exposure to concentrated ambient PM2. 5 via Aryl hydrocarbon receptor. Int Immunopharmacol 2019;77:105939.

12. Harrison RM, Laxen D, Moorcroft S, Laxen K. Processes affecting concentrations of fine particulate matter (PM2. 5) in the UK atmosphere. Atmos Environ 2012;46:115-24.

13. Cortez-Lugo $\mathrm{M}$, Riojas-Rodríguez $\mathrm{H}$, Moreno-Macías $\mathrm{H}$, Montes S, Rodríguez-Agudelo Y, Hernández-Bonilla $\mathrm{D}$, et al. Evaluation of the effect of an environmental management program on exposure to manganese in a mining zone in Mexico. Neurotoxicology 2018;64:142-51.

14. Oh SM, Kim HR, Park YJ, Lee SY, Chung KH. Organic extracts of urban air pollution particulate matter (PM2. 5)-induced genotoxicity and oxidative stress in human lung bronchial epithelial cells (BEAS-2B cells). Mutat Res Genet Toxicol Environ Mutagen 2011;723:142-51.

15. Fuentes-Mattei E, Rivera E, Gioda A, Sanchez-Rivera D, Roman-Velazquez FR, Jimenez-Velez BD. Use of human bronchial epithelial cells (BEAS-2B) to study immunological markers resulting from exposure to PM2. 5 organic extract from Puerto Rico. Toxicol Appl Pharmacol 2010;243:381-9.

16. Gualtieri M, Øvrevik J, Holme JA, Perrone MG, Bolzacchini E, Schwarze PE, et al. Differences in cytotoxicity versus proinflammatory potency of different PM fractions in human epithelial lung cells. Toxicol in vitro 2010;24:29-39.

This is an open access article distributed under the terms of the Creative Commons Attribution-NonCommercial-ShareAlike 3.0 License, which allows others to remix, tweak, and build upon the work non-commercially, as long as the author is credited and the new creations are licensed under the identical terms

This article was originally published in a special issue, "Biomedical Research in Clinical and Preclinical Pharmaceutics" Indian J Pharm Sci 2020:82(3)Spl issue7;53-58 